\title{
Digestibilidade aparente de dietas práticas com diferentes relações energia:proteína em juvenis de pirarucu
}

\author{
Eduardo Akifumi Ono(1), Érica da Silva Santiago Nunes(1), Jimmy Carlos Campos Cedano(1), \\ Manoel Pereira Filho ${ }^{(1)}$ e Rodrigo Roubach ${ }^{(1)}$
}

\begin{abstract}
(1)Instituto Nacional de Pesquisas da Amazônia, Coordenação de Pesquisas em Aqüicultura, Av. André Araújo, no 2936, Aleixo, Caixa Postal 478, CEP 69060-001 Manaus, AM. E-mail: onoedu@yahoo.com, ericassn@inpa.gov.br, jimmycamposx@hotmail.com, pmanoel@inpa.gov.br, roubach@inpa.gov.br
\end{abstract}

\begin{abstract}
Resumo - O objetivo deste trabalho foi determinar a digestibilidade aparente de nutrientes e energia de dietas para juvenis de pirarucu, Arapaima gigas. Foram testadas oito dietas, contendo quatro relações energia:proteína $(11,10,1,9,8$ kcal energia digestível por grama de proteína bruta) e duas fontes de energia não-protéica (óleo de soja e gordura de aves), em esquema fatorial $4 \times 2$, com três repetições. Foram estocados 240 juvenis de pirarucu com peso de 96,8 $\pm 2,3$ g, distribuídos em 24 tanques cilíndricos com fundo cônico, adaptados para a coleta de fezes (sistema Guelph modificado). Os peixes foram alimentados duas vezes ao dia até a saciedade aparente com as dietas experimentais contendo $0,5 \%$ de óxido de cromo, como marcador inerte para determinação dos coeficientes de digestibilidade aparente. As dietas com a relação energia:proteína de 9 kcal energia digestível por grama de proteína bruta apresentaram os menores coeficientes de digestibilidade aparente da matéria seca, proteína bruta e extrativo não nitrogenado. $\mathrm{O}$ maior coeficiente de digestibilidade aparente da gordura foi obtido com o uso do óleo de soja. A relação energia:proteína na dieta influencia os coeficientes de digestibilidade aparente dos macronutrientes e energia no pirarucu.
\end{abstract}

Termos para indexação: Arapaima gigas, energia bruta, nutrição de peixes, proteína.

\section{Apparent digestibility coefficient of practical diets with different energy:protein ratios for pirarucu juveniles}

\begin{abstract}
The objective of this work was to determine the apparent digestibility of nutrients and energy of diets for pirarucu (Arapaima gigas) juveniles. Eight experimental diets containing four energy:protein ratios (11, 10.1, $9,8 \mathrm{kcal}$ digestible energy per gram of crude protein) and two non-protein energy sources (soybean oil and poultry fat) were tested in a $4 \times 2$ factorial scheme, in triplicates. Two hundred and forty pirarucu juveniles weighting $96.8 \pm 2.3 \mathrm{~g}$ were distributed in 24 cylindrical-conical fiberglass tanks, adapted for feces collection (modified Guelph system). Fish were fed twice a day to apparent satiation, with experimental diets containing $0.5 \%$ of chromium oxide as inert marker in order to determine the apparent digestibility coefficients. Diets containing an energy:protein ratio of 9 kcal digestible energy per gram of crude protein resulted in significantly lower apparent digestibility coefficient for dry matter, crude protein and non-nitrogenous extract. The highest apparent digestibility coefficients for crude fat was obtained with soybean oil. The dietary energy:protein ratio influences the nutrient and energy apparent digestibility coefficients to pirarucu juveniles.
\end{abstract}

Index terms: Arapaima gigas, crude energy, fish nutrition, proteins.

\section{Introdução}

O pirarucu, Arapaima gigas, está entre os maiores representantes da ictiofauna que habita as águas doces do mundo. Possui respiração aérea obrigatória, hábito alimentar carnívoro, é rústico ao manuseio em ambientes tropicais, podendo facilmente ser condicionado a aceitar ração extrusada, alcança $10 \mathrm{~kg}$ de peso no primeiro ano de criação (Carvalho \& Nascimento, 1992; Imbiriba, 2001) e tolera altas densidades de estocagem, características desejáveis para a piscicultura intensiva. Considerando as características zootécnicas desejáveis e o alto valor de mercado que a espécie atinge, o pirarucu está entre as espécies de maior potencial para o desenvolvimento da piscicultura na Amazônia, tendo sido 
eleita espécie prioritária para o desenvolvimento da aqüicultura na Região Norte (Queiroz et al., 2002).

Esse grande potencial da espécie para a piscicultura tem atraído o interesse de pequenos produtores e de empresários. Porém, para que o pirarucu possa se estabelecer na piscicultura de forma sustentável é necessário que a espécie seja produzida utilizando rações nutricionalmente completas e balanceadas (Cavero et al., 2003).

Ao contrário dos animais endotermos, os peixes necessitam de maior quantidade de proteína na ração e possuem baixa exigência em energia (Lovell, 1998). Essa energia contida na ração é utilizada na manutenção do metabolismo, locomoção, reprodução e transformação da proteína em crescimento do tecido muscular (Meyer et al., 2004).

Geralmente, rações utilizadas na alimentação de peixes carnívoros contêm elevada concentração de proteína animal, apresentando alto custo e fazem com que os peixes excretem níveis elevados de fósforo e nitrogênio, contribuindo para eutrofização das águas (Kubitza, 2003; Read \& Fernandes, 2003). Segundo McGoogan \& Gatlin (2003), as rações que eram apenas desenvolvidas para maximizar o crescimento dos peixes, agora devem atender a outras necessidades, como a sustentabilidade ambiental das criações, o que pode ser atingido pela otimização do uso dos nutrientes nas dietas, utilizando, para isso, um adequado balanço entre a energia e a proteína.

A energia pode reduzir ou aumentar as taxas de crescimento do peixe e o consumo de alimento (National Research Council, 1993). Rações que contém relações entre energia e proteína elevadas resultam em menor consumo voluntário pelos peixes (Lovell, 1998; Meyer \& Fracalossi, 2004). Além disso, há maior deposição de gordura visceral, pequena ingestão de proteína e outros nutrientes essenciais, prejudicando o desempenho zootécnico, reduzindo o rendimento de carcaça e a vida de prateleira do produto final (Sampaio et al., 2000).

Por sua vez, rações com baixa relação entre energia e proteína induzem os peixes a utilizarem grande parte da proteína ingerida como fonte de energia, afetando o desempenho zootécnico e causando prejuízo econômico, uma vez que a proteína é um dos nutrientes de maior custo nas dietas (Meyer \& Fracalossi, 2004; Skalli et al., 2004). Outra conseqüência do uso da proteína como fonte de energia pelos peixes é o aumento da excreção nitrogenada na água, produzindo um efluente com maior potencial poluente (Kaushik \& Oliva-Teles, 1985).
Rações com balanceamento adequado entre a energia e a proteína permitem maior ganho de peso aos peixes e conversão alimentar eficiente, características desejáveis ao produtor, e baixo acúmulo de gordura na carcaça, característica desejável para o consumidor (Sampaio et al., 2000; Meyer et al., 2004).

Tendo em vista que o conhecimento sobre a influência da relação energia:proteína sobre a digestibilidade das dietas dos peixes é escassa, assim como sobre as exigências nutricionais do pirarucu, a determinação da capacidade dessa espécie em digerir diferentes dietas é uma das etapas primordiais para subsidiar estudos mais detalhados sobre suas necessidades nutricionais.

O objetivo deste trabalho foi determinar os coeficientes de digestibilidade aparente dos macronutrientes, matéria seca e da energia bruta em rações contendo quatro relações energia e proteína e duas fontes de energia não-protéica para juvenis de pirarucu.

\section{Material e Métodos}

O trabalho foi realizado no Laboratório de Nutrição de Peixes da Coordenação de Pesquisas em Aqüicultura (CPAQ) do Instituto Nacional de Pesquisa da Amazônia (Inpa), entre os meses de agosto de 2004 e março de 2005. Juvenis de pirarucu adquiridos de uma piscicultura comercial em Iranduba, AM, foram condicionados à aceitação de ração seca, segundo Ono et al. (2003). Depois do condicionamento alimentar, os peixes foram mantidos em tanque-rede de $1 \mathrm{~m}^{3}$ dentro de um viveiro de $50 \mathrm{~m}^{2}$ até o início do experimento.

Duzentos e quarenta juvenis de pirarucu com peso de $96,8 \pm 2,3 \mathrm{~g}$ foram distribuídos aleatoriamente em 24 tanques cilíndricos com fundo cônico, contendo $80 \mathrm{~L}$ de água, equipados com coletor de fezes (sistema Guelph modificado). Cada tanque foi abastecido com fluxo contínuo de água (1 L por min) proveniente de poço semiartesiano e aeração contínua para adequada qualidade da água.

As rações foram elaboradas em lotes individuais, a partir de ingredientes finamente moídos $(<850 \mu \mathrm{m})$ que foram misturados, umedecidos com $350 \mathrm{~mL}$ de água por quilograma e peletizados usando um picador de carne com matriz de diâmetro de $6 \mathrm{~mm}$. Os péletes foram secados em estufa a $50^{\circ} \mathrm{C}$ por 8 horas, resfriados, embalados e mantidos em freezer até o uso. Em um delineamento fatorial $4 \times 2$, foram testadas quatro relações energia:proteína $\left(11,10,1,9\right.$ e $8 \mathrm{kcal} \mathrm{g}^{-1}$ de proteína) e duas fontes de energia, uma vegetal (óleo de soja) e outra 
animal (gordura de aves), totalizando oito dietas experimentais (Tabela 1), com três repetições por tratamento. Os peixes foram alimentados duas vezes ao dia (8 e 15h) até a saciedade aparente com as dietas experimentais. Os peixes foram considerados saciados quando cessaram a subida à superfície para a captura do alimento ofertado.

A qualidade da água dos tanques foi monitorada por meio de medição diária das concentrações de oxigênio dissolvido $\left(\mathrm{mg} \mathrm{L}^{-1}\right)$, temperatura $\left({ }^{\circ} \mathrm{C}\right), \mathrm{pH}$, condutividade elétrica $\left(\mu \mathrm{S} \mathrm{cm}^{-2}\right)$ e medição semanal da concentração de amônia total $\left(\mathrm{NH}_{3}+\mathrm{NH}_{4}{ }^{+}, \mathrm{mg} \mathrm{L}^{-1}\right)$.

Os coeficientes de digestibilidade aparente (CDA) da matéria seca (MS), proteína bruta (PB), extrato etéreo (EE), extrativo não nitrogenado (ENN) e energia bruta (EB) das dietas foram determinados segundo Furukawa \& Tsukahara (1966), utilizando-se como marcador inerte $0,5 \%$ de óxido de cromo $\left(\mathrm{Cr}_{2} \mathrm{O}_{3}\right)$ nas rações, e sua concentração foi determinada nas fezes.

Os peixes foram alimentados com rações experimentais contendo o marcador inerte durante uma semana, antes do início das coletas, para garantir a eliminação de alimento, sem o marcador, do trato digestivo. As fezes foram coletadas em intervalos de $20 \mathrm{~min}$ (para evitar perdas por lixiviação) em recipientes de vidro e imediatamente congeladas, até que fossem recolhidas quantidades suficientes de cada amostra para a análise. Após o término da coleta de todas as amostras, as fezes foram liofilizadas para determinar a composição centesimal e a concentração de óxido de cromo.
A análise da composição centesimal das amostras de cada uma das rações experimentais e das fezes coletadas correspondentes aos oito tratamentos foi realizada segundo Association of Official Analytical Chemists (1999).

A determinação de umidade foi realizada em duas etapas: pré-secagem - liofilização das amostras por sublimação do gelo a $-40^{\circ} \mathrm{C}$ e posterior equilíbrio com a umidade ambiente; matéria seca (MS) - baseada na determinação da perda de peso das amostras submetidas ao aquecimento em estufa a $105^{\circ} \mathrm{C}$ até peso constante. A umidade total foi obtida pela somatória da umidade resultante na liofilização e na estufa a $105^{\circ} \mathrm{C}$.

A quantidade de proteína nas amostras foi calculada pelo método de micro-Kjeldahl. As concentrações de proteína bruta das amostras foram calculadas multiplicando os valores de nitrogênio total pelo fator de conversão desses valores em proteína bruta ( $\mathrm{N}$ x 6,25), expressos em base seca. Os teores de extrato etéreo (fração lipídica) foram determinados por extração contínua com o solvente de éter de petróleo em extrator intermitente (aparelho Soxhlet).

A energia bruta $\left(\mathrm{kcal} \mathrm{g}^{-1}\right)$ das amostras de rações e fezes foi calculada segundo Lovell (1998) e National Research Council (1993), considerando-se que a proteína gera $5,7 \mathrm{kcal} \mathrm{g}^{-1}$, a gordura gera $9,5 \mathrm{kcal} \mathrm{g}^{-1} \mathrm{e}$ o carboidrato gera $4,1 \mathrm{kcal} \mathrm{g}^{-1}$. Os valores dos coeficientes de digestibilidade aparente (CDA) da matéria seca (MS) e dos nutrientes (Nutr.) foram determinados de acordo com as seguintes equações (Cho et al., 1985; Shipton \& Britz, 2001):

Tabela 1. Composição das dietas práticas com quatro relações entre energia e proteína e duas fontes de energia não-protéica para juvenis de Arapaima gigas.

\begin{tabular}{|c|c|c|c|c|c|c|c|c|}
\hline \multirow[t]{3}{*}{ Ingredientes (\%) } & \multicolumn{8}{|c|}{ Proteína bruta na dieta $(\%)$} \\
\hline & \multicolumn{2}{|c|}{36} & \multicolumn{2}{|c|}{40} & \multicolumn{2}{|c|}{44} & \multicolumn{2}{|c|}{48} \\
\hline & R 1 & R 2 & R3 & $\mathrm{R} 4$ & R 5 & R 6 & R 7 & R 8 \\
\hline Farelo de soja & 15,0 & 15,0 & 15,0 & 15,0 & 15,0 & 15,0 & 15,0 & 15,0 \\
\hline Quirera de arroz & 25,2 & 25,2 & 21,0 & 21,0 & 20,0 & 20,0 & 20,0 & 20,0 \\
\hline Farinha de peixe & 30,0 & 30,0 & 36,0 & 36,0 & 45,0 & 45,0 & 55,0 & 55,0 \\
\hline Farinha de carne e osso & 15,0 & 15,0 & 15,0 & 15,0 & 9,8 & 9,8 & 3,5 & 3,5 \\
\hline Óleo de soja & 0,0 & 14,0 & 0,0 & 12,2 & 0,0 & 9,4 & 0,0 & 5,7 \\
\hline Gordura de aves & 14,0 & 0,0 & 12,2 & 0,0 & 9,4 & 0,0 & 5,7 & 0,0 \\
\hline Suplemento vitamínico e mineral $^{(1)}$ & 0,8 & 0,8 & 0,8 & 0,8 & 0,8 & 0,8 & 0,8 & 0,8 \\
\hline Total & 100,0 & 100,0 & 100,0 & 100,0 & 100,0 & 100,0 & 100,0 & 100,0 \\
\hline Proteína bruta $(\mathrm{PB})(\%)^{(2)}$ & \multicolumn{2}{|c|}{36,3} & \multicolumn{2}{|c|}{40,0} & \multicolumn{2}{|c|}{43,9} & \multicolumn{2}{|c|}{48,0} \\
\hline 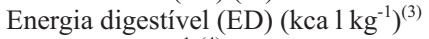 & \multicolumn{2}{|c|}{4.021} & \multicolumn{2}{|c|}{4.022} & \multicolumn{2}{|c|}{3.965} & \multicolumn{2}{|c|}{3.858} \\
\hline ED:PB $\left(\mathrm{kcal} \mathrm{g}^{-1}\right)^{(4)}$ & \multicolumn{2}{|c|}{11,0} & \multicolumn{2}{|c|}{10,1} & \multicolumn{2}{|c|}{9,0} & \multicolumn{2}{|c|}{8,0} \\
\hline
\end{tabular}

${ }^{(1)}$ Enriquecimento de microminerais e vitaminas em mg kg-1 de ração: $\mathrm{Mg}(26)$; Zn (140); Fe (100); Cu (14); Co (0,2); I (0,6); Se (0,6), Vit. A (10.000 UI); Vit. D3 (4.000 UI); Vit. E (100); Vit. K (5); Vit. B1 (25); Vit. B2 (25); Vit. B6 (25); Vit. B12 (30); niacina (100); ácido fólico (5); ácido pantotênico (50); biotina (0,8); colina (2.000); inositol (50); Vit. C (350). ${ }^{(2)}$ Calculada a partir da análise dos ingredientes. ${ }^{(3)}$ Calculada com base na energia digestível dos ingredientes segundo o National Research Council (1993) e Sullivan \& Reigh (1995). ${ }^{(4)}$ Energia digestível (kcal por $100 \mathrm{~g}$ )/Proteína bruta (g por $100 \mathrm{~g}$ ). 
$\mathrm{CDA}_{\mathrm{MS}}=100\left[1-\left(\% \mathrm{Cr}_{2} \mathrm{O}_{3}\right.\right.$ dieta $) /\left(\% \mathrm{Cr}_{2} \mathrm{O}_{3}\right.$ fezes $\left.)\right] ;$ $\mathrm{CDA}_{\text {Nutr. }}=100\left[1-\left(\% \mathrm{Cr}_{2} \mathrm{O}_{3}\right.\right.$ dieta $/ \% \mathrm{Cr}_{2} \mathrm{O}_{3}$ fezes $) \mathrm{x}$ (\% Nutr. fezes $/ \%$ Nutr. dieta)].

Os resultados dos parâmetros físico-químicos da água e os coeficientes de digestibilidade aparente foram submetidos à análise de variância (Two-way ANOVA) a $5 \%$ de probabilidade e quando encontradas diferenças significativas, as médias foram separadas usando o teste Unequal N HSD, a 5\% de probabilidade, com o auxílio do programa StatSoft Statistica versão 6.0 (Cunha et al., 2003).

\section{Resultados e Discussão}

Os parâmetros físico-químicos da água permaneceram uniformes ao longo do experimento, não apresentando diferença significativa entre tratamentos $(p>0,05)$. Os valores dos parâmetros medidos foram: oxigênio dissolvido $\left(6,2 \pm 0,6 \mathrm{mg} \mathrm{L}^{-1}\right)$; temperatura $\left(28,7 \pm 0,9^{\circ} \mathrm{C}\right) ; \mathrm{pH}$ (5,8 $\pm 0,4)$; condutividade elétrica $\left(22,7 \pm 3,5 \mu \mathrm{S} \mathrm{cm}^{-2}\right)$ e amônia total $\left(0,01 \pm 0,005 \mathrm{mg} \mathrm{L}^{-1}\right.$ de $\left.\mathrm{NH}_{3}+\mathrm{NH}_{4}^{+}\right)$, permanecendo dentro da faixa sugerida para as espécies de peixes tropicais (Kubitza, 2003).

A análise centesimal das rações experimentais com marcador inerte é apresentada na Tabela 2 e as concentrações dos macronutrientes das rações foram condizentes com a composição da formulação apresentada na Tabela 1. Os CDAs de cinzas das dietas com diferentes relações energia:proteína não apresentaram diferenças estatísticas entre si $(p>0,05)$. Por sua vez, os CDAs da MS, PB, EE, ENN e EB apresentaram diferenças significativas. Os menores valores resultaram das relações 9 e $8 \mathrm{kcal} \mathrm{g}^{-1}(\mathrm{p}<0,05)$ (Tabela 3$)$.

Tabela 2. Composição centesimal de dietas práticas para juvenis de Arapaima gigas, com quatro relações entre energia e proteína e duas fontes de energia não-protéica.

\begin{tabular}{rccccccc}
\hline E:P & $\begin{array}{l}(1) \\
\text { Fonte de } \\
\text { energia }^{(2)}\end{array}$ & Umid. & PB $^{(3)}$ & Cinzas $^{(3)}$ & EE $^{(3)}$ & ENN $^{(4)}$ & EB (kcal) \\
\hline 11,0 & A & 4,5 & 36,6 & 12,2 & 17,2 & 29,5 & 5.160 \\
11,0 & V & 5,4 & 36,4 & 11,9 & 16,9 & 29,3 & 5.166 \\
10,1 & A & 4,3 & 39,5 & 13,0 & 16,4 & 26,8 & 5.127 \\
10,1 & V & 5,6 & 40,1 & 12,5 & 16,2 & 25,6 & 5.168 \\
9,0 & A & 4,0 & 44,0 & 11,9 & 14,0 & 26,1 & 5.113 \\
9,0 & V & 5,7 & 43,6 & 11,6 & 14,0 & 25,2 & 5.134 \\
8,0 & A & 4,0 & 49,3 & 10,4 & 10,1 & 26,2 & 5.047 \\
8,0 & V & 5,9 & 47,9 & 10,2 & 10,0 & 26,1 & 5.044 \\
\hline
\end{tabular}

${ }^{(1)}$ Relação energia:proteína em kcal por grama de proteína. ${ }^{(2)}$ A: gordura de aves; V: óleo de soja. ${ }^{(3)}$ Valores em base de matéria original da ração (PB: proteína bruta; EE: extrato etéreo). ${ }^{(4)}$ ENN (extrativo não nitrogenado $)=100-($ Umidade $+\mathrm{PB}+\mathrm{Cinzas}+\mathrm{EE}) .{ }^{(5)}$ Energia bruta calculada considerando que a PB gera 5,7 $\mathrm{kcal} \mathrm{g}^{-1}$, o EE gera 9,5 $\mathrm{kcal} \mathrm{g}^{-1}$ e o ENN gera $4,1 \mathrm{kcal} \mathrm{g}^{-1}$.
Esses resultados corroboram as observações de Peres \& Oliva-Teles (1999), que demonstraram que o aumento na relação energia:proteína e na quantidade de gordura na dieta resultou no aumento dos coeficientes de digestibilidade aparente da energia e da gordura em juvenis do carnívoro "seabass" (Dicentrarchus labrax). Resultado similar foi encontrado por Regost et al. (2001), que avaliaram a digestibilidade de dietas para o "turbot" (Psetta maxima) com quatro níveis de gordura, concluindo que as dietas com as maiores relações energia:proteína resultaram em maior digestibilidade de energia.

Por sua vez, Santinha et al. (1999) e Boujard et al. (2004) não encontraram correlação entre a digestibilidade da energia, lipídio ou proteína de dietas com diferentes relações energia:proteína para juvenis de "gilthead seabream" (Sparus aurata) e "seabass" (Dicentrarchus labrax), respectivamente. Em estudo realizado com o "Murray cod" (Maccullochella peelli peelli), Gunasekera et al. (2000) encontraram resultado inverso aos de Peres \& Oliva-Teles (1999), Regost et al. (2001) e deste trabalho, em que a redução na relação energia:proteína resultou em aumento na digestibilidade de energia, com exceção da menor relação energia:proteína, em que a digestibilidade diminuiu.

Entre as duas fontes de energia não-protéica, apenas o CDA do extrato etéreo apresentou diferença, sendo o óleo de soja melhor digerido que a gordura de aves (Tabela 4). Menor digestibilidade das gorduras ricas em ácidos graxos saturados, como a gordura de aves, comparado com o óleo de soja, também foi observada por Caballero et al. (2002), que verificaram que a digestibilidade das gorduras saturadas de cadeias mais

Tabela 3. Coeficiente de digestibilidade aparente (CDA) de matéria seca (MS), proteína bruta (PB), cinzas, extrato etéreo (EE), extrativos não nitrogenados (ENN) e energia bruta (EB) de dietas práticas com quatro relações entre energia e proteína para juvenis de Arapaima gigas.

\begin{tabular}{lllll}
\hline Parâmetro & \multicolumn{4}{c}{ Relação entre energia e proteína (kcal g $\left.{ }^{-1}\right)$} \\
\cline { 2 - 5 } & \multicolumn{1}{c}{11,0} & \multicolumn{1}{c}{10,1} & \multicolumn{1}{c}{9,0} & \multicolumn{1}{c}{8,0} \\
\hline CDA MS & $68,3 \pm 0,9 \mathrm{a}$ & $65,5 \pm 2,0 \mathrm{a}$ & $59,3 \pm 5,3 \mathrm{~b}$ & $64,5 \pm 2,3 \mathrm{a}$ \\
CDA PB & $73,4 \pm 2,6 \mathrm{a}$ & $67,4 \pm 1,5 \mathrm{a}$ & $60,6 \pm 5,9 \mathrm{~b}$ & $65,7 \pm 3,4 \mathrm{a}$ \\
CDA cinzas & $70,1 \pm 1,3$ & $68,0 \pm 2,3$ & $66,7 \pm 0,8$ & $72,4 \pm 3,0$ \\
CDA EE & $98,8 \pm 0,5 \mathrm{a}$ & $98,4 \pm 0,2 \mathrm{ab}$ & $97,9 \pm 0,3 \mathrm{bc}$ & $97,4 \pm 0,9 \mathrm{c}$ \\
CDA ENN & $43,6 \pm 3,8 \mathrm{ab}$ & $41,0 \pm 4,6 \mathrm{ab}$ & $32,7 \pm 7,5 \mathrm{~b}$ & $46,6 \pm 1,4 \mathrm{a}$ \\
CDA EB & $74,5 \pm 0,9 \mathrm{a}$ & $71,4 \pm 1,6 \mathrm{ab}$ & $64,7 \pm 4,7 \mathrm{c}$ & $67,7 \pm 2,3 \mathrm{bc}$ \\
\hline
\end{tabular}

(1)Médias seguidas pela mesma letra não diferem entre si pelo teste Unequal N HSD, a 5\% de probabilidade. 
Tabela 4. Coeficiente de digestibilidade aparente (CDA) de matéria seca (MS), proteína bruta (PB), cinzas, extrato etéreo (EE), extrativos não nitrogenados (ENN) e energia bruta (EB) de dietas práticas com duas fontes de energia não-protéica para juvenis de Arapaima gigas $^{(1)}$.

\begin{tabular}{lcc}
\hline Parâmetro & \multicolumn{2}{c}{ Fonte de energia não-protéica } \\
\cline { 2 - 3 } & Óleo de soja & Gordura de aves \\
\hline CDA MS & $65,3 \pm 3,9$ & $63,9 \pm 5,0$ \\
CDA PB & $68,5 \pm 5,7$ & $65,7 \pm 6,1$ \\
CDA cinzas & $69,7 \pm 3,4$ & $68,9 \pm 3,7$ \\
CDA EE & $98,5 \pm 0,5 \mathrm{a}$ & $97,7 \pm 0,8 \mathrm{~b}$ \\
CDA ENN & $40,7 \pm 6,8$ & $41,6 \pm 7,2$ \\
CDA EB & $70,6 \pm 4,1$ & $69,0 \pm 5,1$ \\
\hline
\end{tabular}

${ }^{(1)}$ Médias seguidas pela mesma letra não diferem entre si pelo teste Unequal N HSD, a $5 \%$ de probabilidade.

longas (C18:0) pela truta (Oncorhychus mykiss) é deficiente, devido à interferência dos ácidos graxos saturados na digestibilidade.

Neste mesmo trabalho, os autores afirmam que quantidades significantes de óleos vegetais e animal podem ser usadas nas dietas com alta energia para a truta arco-íris, sem afetar seu crescimento, pois uma mistura balanceada de óleo vegetal e óleo de peixe resultou em satisfatório CDA para os lipídios. Em estudo recente, realizado com a tilápia-vermelha (Oreochromis sp.), Bahurmiz \& Ng (2007) constataram que a digestibilidade dos lipídeos nas dietas suplementadas com óleos ricos em ácidos graxos saturados (óleo de palmáceas) foi significativamente inferior aos da dieta contendo óleo de peixe, rico em ácidos graxos poliinsaturados, como principal fonte de lipídeos.

\section{Conclusões}

1. A relação entre energia e proteína afeta a digestibilidade dos nutrientes da dieta de juvenis de pirarucu.

2. Juvenis de pirarucu digerem melhor a gordura insaturada (óleo de soja) comparado à gordura saturada (gordura de aves).

\section{Agradecimentos}

À Fundação de Amparo à Pesquisa do Estado do Amazonas, ao Conselho Nacional de Desenvolvimento Científico e Tecnológico (CNPq) e à Secretaria Especial de Aqüicultura e Pesca - SEAP, pelo apoio financeiro; ao CNPq, pela concessão de bolsa de pesquisa e de produtividade em pesquisa.

\section{Referências}

ASSOCIATION OF OFFICIAL ANALYTICAL CHEMISTS. Official methods of analysis of the Association of Official Analytical Chemists. $16^{\text {th }}$ ed. Washington: AOAC, 1999. 1141p.

BAHURMIZ, O.M.; NG, W. Effects of dietary palm oil source on growth, tissue fatty acid composition and nutrient digestibility of red hybrid tilapia, Oreochromis sp., raised from stocking to marketable size. Aquaculture, v.262, p.382-392, 2007.

BOUJARD, T.; GÉLINEAU, A.; COVÈS, D.; CORRAZE, G.; DUTTO, G; GASSET, E.; KAUSHIK, S. Regulation of feed intake, growth, nutrient and energy utilization in European sea bass (Dicentrarchus labrax) fed high fat diets. Aquaculture, v.231, p.529-545, 2004.

CABAllero, M.J.; OBACH, A.; ROSENLUND, G.; MONTERO, D.; GISVOLD, M.; IZQUIERDO, M.S. Impact of different dietary lipid sources on growth, lipid digestibility, tissue fatty acid composition and histology of rainbow trout, Oncorhynchus mykiss. Aquaculture, v.214, p.253-271, 2002.

CARVALHO, L.O.D.M.; NASCIMENTO, C.N.B. Engorda de pirarucus, Arapaima gigas, em associação com búfalos e suínos. Belém: Embrapa-CPATU, 1992. 21p. (Circular Técnica, 65).

CAVERO, B.A.S.; ITUASSÚ, D.R.; PEREIRA-FILHO, M.; ROUBACH, R.; BORDINHON, A.M.; FONSECA, F.A.L.; ONO, E.A. Uso de alimento vivo como dieta inicial no treinamento alimentar de juvenis de pirarucu. Pesquisa Agropecuária Brasileira, v.38, p.1011-1015, 2003.

CHO, C.Y.; COWEY, C.B.; WATANABE, T. Finfish nutrition in Asia: methodological approaches to research and development. Ottawa: International Development Research Center, 1985. 154p.

CUNHA, I.; SABORIDO-REY, F.; PLANAS, M. Use of multivariate analysis to assess the nutritional condition of fish larvae from nucleic acids and protein content. The Biological Bulletin, v.204, p.339-349, 2003.

FURUKAWA, A.; TSUKAHARA, H. On the acid digestion method for the determination of chromic oxide as an index substance in the study of digestibility of fish feed. Bulletin of the Japanese Society of Scientific Fisheries, v.32, p.502-506, 1966.

GUNASEKERA, R.M.; DE SILVA, S.S.; COLLINS, S.A.; GOOLEY, G.; INGRAM, B.A. Effect of dietary protein level on growth and food utilization in juvenile Murray cod Maccullochella peelii peelii (Mitchell). Aquaculture Research, v.31, p.181-187, 2000.

IMBIRIBA, E.P. Potencial de criação de pirarucu, Arapaima gigas, em cativeiro. Acta Amazônica, v.31, p.299-316, 2001.

KAUSHIK, S.J.; OLIVA-TELES, A. Effect of digestible energy on nitrogen and energy balance in rainbow trout. Aquaculture, v.50, p.89-101, 1985.

KUBITZA, F. Qualidade da água no cultivo de peixes e camarões. Jundiaí: Kubitza, 2003. 229p.

LOVELL, R.T. Nutrition and feeding of fish. Boston: Kluwer Academic Publishing, 1998. 267p. 
MCGOOGAN, B.B.; GATLIN, D.M. Dietary manipulations affecting growth and nitrogenous waste production of red drum, Sciaenops ocellatus. II. Effects of energy level and nutrient density at various feeding rates. Aquaculture, v.182, p.271285, 2003.

MEYER, G.; FRACALOSSI, D.M. Protein requirement of jundia fingerlings, Rhamdia quelen, at two dietary energy concentrations. Aquaculture, v.240, p.331-343, 2004.

MEYER, G.; FRACALOSSI, D.M.; BORBA, M.R.A. Importância da quantidade de energia na ração de peixes. Panorama da Aqüicultura, v.14, p.53-57, 2004.

NATIONAL RESEARCH COUNCIL. Nutrient requirements of fish. Washington: National Academy Press, 1993. 114p.

ONO, E.A.; ROUBACH, R.; PEREIRA FILHO, M. Pirarucu production: advances in Central Amazon, Brazil. Global Aquaculture Advocate, v.6, p.44-46, 2003.

PERES, H.; OLIVA-TELES, A. Effect of dietary lipid level on growth performance and feed utilization by European sea bass juveniles, Dicentrarchus labrax. Aquaculture, v.179, p.325334, 1999.

QUEIROZ, J.F.; LOURENÇO J.N.P.; KITAMURA, P.C. A Embrapa e a aqüicultura: demandas e prioridades de pesquisa. Brasília: Embrapa Informação Tecnológica, 2002. 35p.
READ, P.; FERNANDES, T. Management of environmental impacts of marine aquaculture in Europe. Aquaculture, v.226, p.139-163, 2003.

REGOST, C.; ARZEL, J.; CARDINAL, M.; ROBIN, J.; LAROCHE, M.; KAUSHIK, S.J. Dietary lipid level, hepatic lipogenesis and flesh quality in turbot (Psetta maxima). Aquaculture, v.193, p.291-309, 2001.

SAMPAIO, A.M.B.M.; KUBITZA, F.; CYRINO, J.E.P. Relação energia: proteína na nutrição do tucunaré. Scientia Agricola, v.57, p.213-219, 2000.

SANTINHA, P.J.M.; MEDALE, F.; CORRAZE, G.; GOMES, E.F.S. Effects of the dietary protein: lipid ratio on growth and nutrient utilization in gilthead seabream (Sparus aurata L.). Aquaculture Nutrition, v.5, p.147-156, 1999.

SHIPTON, T.A.; BRITZ, P.J. An assessment of the use of chromic oxide as a marker in protein digestibility studies with Haliots midae L. Aquaculture, v.203, p.69-83, 2001.

SKALLI, A.; HIDALGO, M.C.; ABELLÁN, E.; ARIZCUN, M.; CARDENETE, G. Effects of the dietary protein/lipid ratio on growth and nutrient utilization in common dentex (Dentex dentex L.) at different growth stages. Aquaculture, v.235, p.1-11, 2004.

SULLIVAN, J.A.; REIGH, R.C. Apparent digestibility of selected feedstuffs in diets for hybrid striped bass (Morone saxatilis female x Morone chrysops male). Aquaculture, v.138, p.313-322, 1995.

Recebido em 21 de junho de 2007 e aprovado em 7 de fevereiro de 2008 